\title{
SIMON NEWCOMB.
}

Simon Newcomb was born on March 12, 1835, at Wallace, Cumberland County, Nova Scotia. His parents were of New England descent temporarily settled there. He was educated by his father, and at the age of sixteen was apprenticed to a local herb doctor, but left him after two years and made his way to Maryland, in which State he spent four years teaching in various schools. An appointment on the staff of the Nautical Almanac took him to Cambridge, the headquarters of the office at that time, and he found opportunities to attend the Lawrence Scientific School, where he took the degree of B.Sc. in 1858. In 1861 he was appointed professor in the United States Navy and was detailed for work at the Naval Observatory in Washington. In 1877 he was made Superintendent of the American Ephemeris and Nautical Almanac office, and occupied this post for the next twenty years until his compulsory retirement under the regulations at the age of sixty-two. During this period he lectured for one year on political economy at Harvard, and from 1884 to 1895 was professor of mathematics and astronomy at Johns Hopkins University, and editor of the American Journal of Mathematics. After his retirement he continued to live and work in Washington until his death on July 11, 1909.

In 1863 he married Mary Caroline Hassler, daughter of Dr. Charles A. Hassler, U. S. Navy. His widow and three daughters survive him.

Newcomb's boyhood in a village community where life is hard and strenuous must have been full of the minor privations of life characteristic of early New England and Canadian traditions, but modified by the conditions under which he was brought up. His father was a school teacher, frequently changing from one place to another, and evidently a man of ideas more advanced than those of his generation with respect to education. Although he had to conform to current practices in the country schools where he taught, he seems to have felt that his own boy should have more mental freedom. He must have studied carefully the capacities of the young Simon and noted the direction which they took, for he made no effort to force him into work for which he was not adapted. But few books were obtainable, and those which were read were of little 
intrinsic value. In his Reminiscences Newcomb says that his earliest ideas were chiefly influenced by Fowler's Phrenology and Combe's Constitution of Man. We can only judge from this that Newcomb was one of those lonely spirits that will achieve their development under any conditions, provided sufficient freedom of thought is allowed.

His somewhat erratic school education was closed at the age of sixteen by his apprenticeship to a man whose influence was of the worst possible kind for a young lad just growing into manhood. The picture which Newcomb draws of Dr. Foshay, a medical Squeers, would be notable as fiction; as a description of real life it gives one cause to wonder at the strength of character of the boy who could withstand the insidious council : "This world is all a humbug, and the biggest humbug is the best man." Fortunately, the boy had one keen desire, to learn and to know, and the unsatisfied longing finally drove him to run away from his legal master and return to his father in Maryland. He abandoned finally the idea of becoming a doctor and while in doubt as to his future career earned his living by teaching.

He evidently found time for a good deal of study in the few and second-grade books that he was able to find. Perhaps the very poverty of their treatment stimulated him to make efforts of his own, for we find him shortly afterwards sending a new proof of the binomial theorem to Professor Henry, and later answering a "crank" theorist on the Copernican doctrine in the columns of the National Intelligencer-his first publication. These efforts brought him to the notice of one or two scientific men, and he was not slow to avail himself of the advantages for the further pursuit of knowledge which were to be obtained through them. He discovered Bowditch's translation of Laplace and obtained a Nautical Almanac; from that time on, the main direction of his studies was never in doubt.

Although he was nominally a student of the Lawrence Scientific School for a year, and received his degree from that institution, there can be no doubt that Newcomb was, like the majority of men of his generation in America who have attained scientific fame beyond the shores of the continent, essentially self-taught. His opportunities could scarcely have been more meagre in quality or quantity, but he let none of them slip by unutilized in his desire to learn. During his four years of experience in Cambridge as a computer on the Nautical 
Almanac, he came into contact with Benjamin Peirce, B. A. Gould, Runkle, and Safford, and from them he doubtless learned much, directly and indirectly; his early tendencies there received a definite scientific trend.

It was during this period that he began an investigation which resulted in the publication of one of his most important papers. At that time only a few of the minor planets had been discovered, and several theories had been put forward to account for their existence. Newcomb, collecting the various elements of these small bodies, applied to them the theory of perturbations, and showed that the distribution of their nodes and perihelia is quite arbitrary within the limits of error, and further that there was no point at which all the orbits could have intersected at any time in the past. This was generally considered as disposing of the explosion theory of Olbers. Newcomb recognized, however, that it was by no means certain that the criterion applied is sufficient. The mechanical conditions of such a swarm, under collisions and the disturbances caused by other planets, may ultimately result in an apparently arbitrary distribution. What is more interesting is the fact that even at this early date Newcomb shows in these papers that grasp of the general principles of celestial mechanics and the methods of dealing with observations, which has always been such a marked feature of all his researches. It is, in fact, a key-note to his work.

The small planets continued to interest him for several years, both in bulk and individually. We find several papers on the subject, even up to the year 1900 , and he had the management of the asteroids which had been "endowed" by Watson.

His appointment as professor in the United States Navy and removal to the Observatory at Washington gave him his first opportunity to become acquainted with the practical side of astronomy. The somewhat chaotic state of the administration during the war, and for some time afterwards, again gave him the freedom to develop the subjects which interested him. Although he was making routine observations during this period, the papers which were published under his name show that his interests lay in other directions. Positional astronomy was always connected in his mind with some theory. His published papers are rarely mere sets of observations, and more generally were deductions made from the observations of others. As his knowledge gradually extended in range from the fixed 
stars to the moon, he was becoming more and more impressed with the confusion creeping into exact astronomy by the different values of the constants used by different observers. He was ambitious in his programme for the future, and two plans were maturing in his mind. The first was a determination of all the constants of astronomy and their reduction to a homogeneous system. He soon saw that this would involve extended work on the theories of the planets and satellites in order to make the comparisons with observations free from empirical terms. The second problem was more special, and though not likely to demand so much time, more difficult, - the resolution of the lunar motions and the test of the law of gravitation which a comparison with the lunar theory would involve. All of his best scientific work was directed towards these two ends.

In the period between 1861 and 1877, when he became Director of the Nautical Almanac and was in a position to carry out his larger projects, his mind was active in many directions. We find short notes on a variety of subjects, - optics, finance, taxation, social science, the labor question, copyright, political economy, non-euclidean geometry. He wrote numerous reviews and popular articles, chiefly on astronomical matters. Whatever may be the ultimate fate of the views which he expressed, one feature of his writings could not fail to be valuable: he never left the reader in doubt as to his meaning. Any difficulty would be stated with that clearness and freedom from unessential detail which characterized everything he said or wrote.

By the age of thirty, and within a very few years after his arrival in Washington, Newcomb had "found himself." He had definite plans for his future, and these were more than sufficient to occupy the life-time of one man. His more important contributions to celestial mechanics were thought out before 1870 , and he had a sufficiently wide knowledge of the problems of astronomy to pursue his work steadily. In fact, one sees only occasional flashes of originality after this time; he seemed to be too busy on his chosen plans to give deep thought to novelties. It is difficult to notice much difference between his earlier and his later papers, either in power or breadth of treatment. Knowledge naturally increased and he kept fully abreast of contemporary work in the astronomy of position, so that at the time of his death he was undoubtedly its chief exponent, and he may perhaps, without injustice to his predecessors, be given the foremost place amongst those who have labored for the development of this subject. 
From this point on it seems proper to speak of the development of his ideas with reference to subject matter rather than in chronological order.

The position of Mars in 1862 suggested a redetermination of the solar parallax, both from the observations of that year and from all previous observations and methods. His concluded value, $8^{\prime \prime} .848$, was larger than the latest determination of that much discussed constant, and in the final summary of his life-work contained in the Constants of Astronomy he abandoned it for the value $8^{\prime \prime} .790$, which is quite close to the latest value $8^{\prime \prime} .806$, derived by Hinks from observations of Eros. The question depends mainly on the weights to be attributed to the results obtained by different methods.

In the same line of thought is his reduction of star places in different catalogues to a homogeneous system. Each observer appears to have had his own method for reducing his observations. Any one undertaking an investigation which involved the use of different catalogues of stars was obliged to find out, first of all, how the observations had been treated. "Newcomb's aim," says Dr. Hill,* "was to eliminate as far as possible systematic errors of a personal or local nature and thus obtain a homogeneous system. This is an admirably conducted investigation and has served as a foundation for whatever has been since accomplished in this subject."

Another problem, necessary for knowledge of the constant of aberration, was a fresh determination of the velocity of light. This had been undertaken by Michelson, and though Newcomb carried through a separate investigation, partly with the help of Michelson, the results were not entirely satisfactory, and the final determination rested mainly on the former investigation. The constants of precession and nutation were also obtained. With the former appeared a catalogue of fundamental stars. The methods caused a somewhat lively discussion.

Newcomb's plans for new tables of the motions of the planets involved a recalculation of their orbits. He had already investigated those of Uranus and Neptune. What had to be done was to calculate afresh the orbits of the other planets, gather all known observations together, compare them with his preliminary tables of the planets so as to correct the constants and show any deviation not accounted for by theory, and then make final tables on a uniform system of constants. This work

* Science, September 17, 1909. 
occupied more than twenty years. Nearly all of it was published in a series of volumes founded by Newcomb and entitled: Astronomical Papers prepared for the use of the American Ephemeris and Nautical Almanac.

In starting to compute the planetary perturbations Newcomb had a choice of three methods. There was the direct method of obtaining a solution of the equations in polar coordinates, by which Laplace had treated the planetary theory; there was the method known as the variation of arbitrary constants, which had been used by Leverrier ; and there was the peculiar method of Hansen. Newcomb seems to have been troubled all through his life by the difficulty of mastering complicated analysis, and always turned by preference to a simple theory which could without much trouble be prepared for computers. He thus used, at the start, Laplace's method, and we find it adopted in all his planetary theories. But he was not satisfied with Leverrier's development of the disturbing function, and some of his earliest attempts were directed towards improvements in this direction. He saw a simple method of starting by means of the eccentric anomalies, and one of his long papers contains a complete development on these lines. But he afterwards found that it did not work very well, and later he returned to the Leverrier method, with certain improvements which rendered the computations more simple.

This concluded, he was able to undertake the orbits of the four inner planets. Approximate elements only are needed in finding the perturbations, since any changes in the constants can be made easily. The elements of Leverrier served for this purpose. The investigation is published in detail in Volume III of the Astronomical Papers, and it is, at the present time, the best theory of these planets that we have. With somewhat more care it might have been made final, but knowing that his term of office was drawing to a close Newcomb seems to have been in somewhat of a hurry to finish. The calculations were executed in duplicate by computers, and the two sets of results, together with those of Leverrier, are printed side by side. In glancing over them one notices here and there considerable differences between the duplicate calculations. It would have been more satisfactory if the sources of these differences had been traced down and corrected. Duplicate calculations are indeed almost essential in such work, but they lose much of 
their value if the errors revealed are not removed. There are also occasional misprints which give a feeling of insecurity to one using any special numbers for other purposes. In a later paper the secular variations of the four planets are computed by Gauss's method.

The theory was not, however, the heaviest part of the work. All known observations had to be collected and compared. It was here that Newcomb's particular genius for the organization of huge masses of material, and his firm grasp of the facts which could be deduced from them, was given free play. Over 62,000 meridian observations of Mercury, Venus, and Mars were employed for those planets alone. The work had to be done with but little addition to the ordinary force of computers employed on the Nautical Almanac. Besides the planetary comparisons, it was necessary to find the corrections to the general constants of the solar system, and also to those of the earth, such as precession and nutation, which affect every observation. All these had to be fused into a homogeneous whole so that the motions of the solar system should be made to depend on one and the same system of constants. This immense mass of work is summarized in a little volume which was published as a Supplement to the Nautical Almanac for 1897, and is entitled : Elements of the Four Inner Planets and the Fundamental Constants of Astronomy, or more briefly, Astronomical Constants. This volume gathers together Newcomb's life-work and constitutes his most enduring memorial.

The mutual perturbations of Jupiter and Saturn are so large that the problem of unravelling their motions is a much more difficult application of the planetary theory than the other six large planets require. For the successful completion of Newcomb's scheme within his life time it was necessary that these two planets should be treated by another hand and he was able to enlist the services of G. W. Hill for this purpose. Hill, indeed not only worked out the theories in full but compared them with observation and formed the tables which were the necessary complement if his labors were to be utilized to their full extent.

The publication of the tables of the planets followed rapidly. All of them bear Newcomb's name, except those of Jupiter and Saturn, for which, as we have just seen, G. W. Hill was entirely responsible. Newcomb was fortunate in securing assistance, not only from a man like Hill with a world-wide reputation, but 
also from others who were far above the grade of ordinary computers, and to whom he was able to explain his methods so that they could carry the work forward with an understanding of what they were doing. Indeed, it would have been impossible for him to have covered the ground effectually without such assistance. The tables themselves contain no very notable features; a few slight improvements may be noted on the general methods for tabulating introduced by Hansen in his tables of the moon.

While carrying forward to successful completion his schemes for the planets, Newcomb continually returned to the subject which interested him above all others - the motion of the moon. As early as 1859 we find him comparing the observed places of the moon with those given in the Ephemeris, and his last paper, not yet published, deals with the same subject. Indeed, he always hoped to be able to add a set of new tables of the moon's motion to his already long list of achievements. That this did not become possible was undoubtedly a source of regret to him. But posterity will accord greater praise for what he did achieve than it would for the mere fulfilment of the ambition of a life-time.

It was not long before Newcomb's advent into the astronomical world that Hansen's tables of the moon had been introduced for the purpose of computing the moon's ephemeris in the Nautical Almanac. It was then thought that they would satisfy all the needs of astronomy. Hansen had said that they satisfied all the observations for a century back, and that the eclipses of ancient times were fairly well acounted for. Shortly before the publication of Hansen's tables, Adams had shown that the change in the mean length of the month was different from that given by Hansen, so different, indeed, that the ancient eclipses could not be reconciled if the new theoretical value were used. Newcomb, always interested in the comparison between theory and observation, wondered if Hansen's tables would agree with observations before 1750 , and he started to look for data which should test the question. Early meridian observations could not be relied on, but occultations are phenomena which even the earliest scientific observers would be apt to note and which are free from many of the errors to which meridian observations are liable. At the first opportunity he went on a search over Europe for such observations. His labor was well rewarded. He was able to find sufficient ma- 
terial for comparison over another century. On working it up he discovered that there was a large periodic change in the moon's longitude not indicated by theory and running through its phases in some three hundred years. The term is still unexplained.

These discoveries necessitated a more careful study of the ancient eclipses in order to see how they were affected. The new periodic term had but little influence on them; the difference between Adams's and Hansen's values for the secular change was the point at issue. In 1878 Newcomb was able to publish the results of his investigations and to give additional tables by means of which the moon would keep more nearly to its predicted place. It is true that the new terms were empirical, but that mattered little for the purposes of the Nautical Almanac. His last memoir, and one of his best, consists of a reexamination of all the known occultations since the beginning of the seventeenth century, including fresh material that he had gathered in the last twenty years. The earlier conclusions are confirmed and one or two new terms of shorter period are brought to light.

It had long been known that Hansen's theoretical investigations of the effects of the planets on the moon's motion were of doubtful accuracy. Newcomb must have had the problem of their determination, and, indeed, the whole question of Hansen's lunar theory in his mind quite early in his career. In 1868 he made a partial comparison with the only other theory approaching it in degree of accuracy, that of Delaunay. The comparison was completed in 1882 by himself and J. Meier, and it showed that the errors of the solar terms were not serious enough to affect the places of the moon when averaged over long periods of time. But Delaunay had not computed the planetary terms. In 1871 Newcomb published a method for finding them. It finally turns out to be practically a continuation of Delaunay's theory but it was far from the stage of numerical application. It was not until twenty-three years later that he continued the idea of that memoir sufficiently far to show its possibilities, though even then nothing like an extensive investigation of the whole subject was attained. Nevertheless, this second memoir is one of his ablest investigations, from the point of view of theory. In it he finds some remarkable relations that arise between the constants in the problem of four bodies. When finally developed, these rela- 
tions reduce the computation of the secular accelerations to a comparatively simple problem. He himself never thought very highly of this paper, mainly because it did not fulfill the object for which it was undertaken.

His work on the subject was only completed in a long paper published a couple of years ago. Although before the appearance of Newcomb's second memoir Hill had given a practical and thoroughly effective method for computing all small perturbations, and in 1891 Radau had developed Hill's idea in considerable detail, Newcomb still clings to his own methods. He felt afterwards that this proceeding had been a mistake. In a letter to the writer he says :

"I now see had I devoted a few days or weeks to carefully studying the phases of the problem as presented not only by yourself, but Delaunay, Radau, and Hill, I might have profited immensely and been able to do my work much more easily as well as to put it into more condensed shape. But I am always repelled by intricate algebraic expressions stringing on without end without any well marked division into parts. Any attempt to manipulate them simply tires me out before I get to the end; so, however complex may be the expressions I have to deal with, I like to cut them up into parts and condense them to handle them. So I went to work trying my system without having sufficiently learned what could be done from the work of others." The whole trouble really consisted in his attempt to develop the disturbing functions by special values instead of by expansion; in spite of the help of computers such a method gives enormous calculations from which comparatively few results are obtained. The final numerical values were unfortunately erroneous in many cases, owing to a slip at the end of the work.

Almost the only excursion that Newcomb made into pure theory is contained in a paper entitled "The general integrals of planetary motion," and it consists of an attempt to show how the coordinates of a planet, under the attraction of any finite number of planets, may be represented by trigonometric series. Poincaré has used this paper as a text for his investigations into the possibilities of such developments. It is, at bottom, an extension of Delaunay's methods to any number of bodies. The various relations between the constants of integration and those present in the developments are worked out with great skill by means of Lagrange's methods for the variation of arbitrary constants. All through his theoretical work Newcomb 
seems to cling to Lagrange's equations and to reach the canonical forms through them rather than to obtain the latter directly through the brief methods of Jacobi. There were, however, certain advantages in so doing. He was able to deduce, in the natural course of the work, the final canonical constants $L, G$, $H$, of Delaunay, directly from the final expressions of the rectangular coordinates in terms of the time. These are important when other perturbations of the moon, beyond those produced by the sun, have to be obtained.

A curious anomaly in the motion of Hyperion, the seventh satellite of Saturn, is satisfactorily explained in Volume III of the Astronomical Papers. Professor Hall had deduced from observation that the point of nearest approach to the planet possesses a large retrograde motion, while the ordinary theories indicate a forward motion. Newcomb traced the difficulty to an approximate commensurability between the mean motions of Hyperion and the disturbing satellite Titan. It is a case of "libration," in which an angular element oscillates instead of making complete revolutions.

In fact, Newcomb frequently had a happy faculty of hitting on the explanation of some curious anomaly and in quickly publishing a brief note on the subject. His suggestion that the difference between the observed period of the motion of the earth's pole and the period demanded by theory is due to the elasticity of the earth, has been fully confirmed by subsequent investigations. In quite another direction was the theorem that " if a fourth dimension were added to space, a closed shell could be turned inside out by flexure without stretching or tearing."

Although the paper just mentioned is perhaps Newcomb's only notable contribution to pure mathematics, he was familiar with the general directions which investigation had taken during the nineteenth century. In his presidential address before the American Mathemetical Society in 1893, he begins with a disclaimer of any right to be considered a mathematician in the modern sense of the word. But from the remarks which follow, it is evident that he had not only read but had devoted some thought to modern ideas on hyperspace, group theory, projective geometry, and the like. What is more interesting is his analysis of the manner in which the thought of the modern mathematician differs from that of the ancients, and his general conclusion that one of the chief advantages of present-day methods is their 
economy in the reduction of the number of mental concepts required to express the same ideas.

Of his numerous contributions to economics I quote the statements of Professor Irving Fisher in the British Royal Economic Journal:

"Personally I would rank Professor Newcomb high as an economist, and am glad to find that in this judgment President Hadley heartily concurs. Doubtless Professor Newcomb leaves a large number of other admirers, yet it would seem that his economic writings did not attract the attention among economists which they deserved. . . .

"Perhaps his chief and most fruitful contribution to economic science was the distinction he showed so clearly between a 'fund' and a 'flow,' a 'fund ' relating to a point of time, and a 'flow' relating to a period of time. This distinction he applied in particular to what he called 'societary circulation,' or the equation of exchange between money and goods. So far as I am aware, he was the first definitely to enunciate this equation expressing the fact that quantity of money multiplied by its velocity of circulation is equal to price level multiplied by volume of business transactions. This equation, with due amplification, represents the so-called 'quantity theory of money' in its highest form. He alone employed this same distinction between a 'fund' and a 'flow' to expose the fallacy of the 'wage-fund.' . . .

"Professor Newcomb's economic writings include many of a controversial nature. He took a vigorous part, for instance, in the discussion some years ago, as to the best standard of deferred payments, and still earlier, in the question of labor and capital. He was an advocate in general of the 'let alone' policy, though he distinguished it sharply from what he called the 'keep out' policy. In other words, he believed in free economic activity of individuals, but did not advocate the exclusion of government from economic activity.

"As to methodology, he believed that economics is a science, and consequently that the method to be followed by economic science should be the same as the method followed by science in general. He emphasized the fact that 'A law of nature can only be expressed in the form of a conditional proposition.' . . .

"In applying this idea he pointed out the fallacy of judging the effect of a tariff by the subsequent rise or fall of prices. The imposition of the tariff, as he pointed out, will make prices 
higher than they otherwise would be, but not necessarily higher than they had been."

He wrote many text-books on astronomy and cognate subjects. His Popular Astronomy ran through many editions and was translated into several languages. A number of elementary text-books on mathematics were not the least of his contributions to education and they exerted considerable influence on the study of mathematics in their time. The long list of nearly four hundred publications, gathered together by Dr. Archibald in Volume XI (1905) of the Transactions of the Royal Society of Canada, shows titles of published addresses, reviews, numerous popular articles, several short stories, and a novel. The last he did not care to discuss, owing to some difficulties which had resulted in its publication before it was in the form in which he would have desired it to come before the public.

Education, its theory and practice, has always been a matter of interest to the people at large in the United States, and Newcomb as a professor at Johns Hopkins University and a writer of text-books naturally spoke on the subject with some authority. He was chairman of the conference on mathematics appointed by the committee on secondary school education in 1892, generally known as the Committee of Ten. The report adopted by this conference has had a large influence on the teaching of mathematics and his share in its preparation was undoubtedly considerable.

If we altempt to judge Newcomb's work, it is necessary to consider the three sides of astronomy in which he was chiefly interested. The first, purely theoretical, consists practically of mathematical investigations; the third, the purely observational side, is the function of the observatory; the second is the combination of these two, the comparison between theory and observation. There can be no doubt that Newcomb's chief title to lasting fame lies in the second of these three directions. He was a master, perhaps as great as any that the world has known, in deducing from large masses of observations the results which he needed and which would form a basis for comparison with theory. Only in his earlier years had he made any observations, and the impression one gets in reading his Reminiscences, conveys the feeling that he never cared much for that department of astronomy. On the purely mathematical side of the problems of celestial mechanics he 
cannot be said to have been thoroughly at home. We have from his pen no new method for dealing with the motions of the bodies in our solar system. On the other hand, he had a thorough grasp of their mechanical relations and this nearly always served his purposes. He had too a remarkable facility for seizing on the essential point of some known method, provided it was not too complicated, improving and then adapting it so that computers could perform nearly all the numerical work. As stated above, Newcomb's predilections alway tended towards some practical result, even when he wrote a purely theoretical paper ; but curiously enough, the two or three papers which represent this side of his work never reached fully successful application at his hands.

In reading Newcomb's papers one becomes impressed with his geometrical point of view of almost every subject. $\mathrm{He}$ seemed doubtful of analysis by means of symbols unless it were possible to get a bird's-eye view of the process and of the manner in which physical principles led up to it. Consequently, errors of theory were unusual in his publications. It has always been a matter of astonishment to the writer how easily either theoretical or numerical errors, when they did occur, could be traced down and corrected. His clear mental view of the problem was reflected in his prose, which, without graces of style, always expressed exactly what he meant.

Newcomb's influence on the thought and men of his times must be judged mainly by the condition in which he found the subjects over which his mind ranged and by his life in a land whose people were passing through the transition stage from a nation of pioneers to a firmly seated world power. Possessed of a broad mind, a wide range of knowledge, and a capacity for taking an interest in almost all matters brought to his attention, he is peculiarly well qualified to stand as a representative of the mental attitude of his generation towards the problems which confronted it. His great power of organization was applied to astronomy at a time when the subject needed just such a man to prevent confusion from falling into chaos. Deep insight was less to be desired than broad comprehension. If it cannot be said of Newcomb that he gave a new set of ideas to the world, there can be no doubt as to the value of his contributions to almost every department of his own science and to many portions of other sciences. Again, he was essentially practical in every undertaking, even to the extent of devoting 
himself during his last years to a problem which he might hope to solve and in avoiding sole responsibility for any large scheme involving many years of labor. Less characteristic of his times was the impersonal attitude which he appeared to have and to expect others to have towards the objects of science. Whether this be judged as a defect or not, the task of a future historian will be rendered more simple by the absence of those qualities which would, if prominent, demand a careful investigation into the unofficial relations with the men of his time in order to obtain an accurate estimate of his influence. He seemed unable or unwilling to give that personal touch to a discussion which has played so large a part in the management of the general affairs of the nation.

Newcomb was indefatigable in his attendance at congresses, scientific meetings, and academic functions. Although he never indulged much in the lighter sides of conversation he was always ready to talk on any subject of real interest. On such occasions he would not hesitate to express any ideas which might occur to him, and sometimes mistook reticence in others for absence of ideas. He was fond of presiding over the deliberations of scientific bodies, and by his own attitude always imparted additional dignity to the proceedings. His great reputation amongst astronomers was combined with extended popular knowledge of his fame, at least on the American continent, and he received unusually numerous evidences of recognition from all parts of the world.

His naïve enjoyment of the honors which he received shows real modesty in his estimate of his own work. In correspondence he would frequently regret its defects and express the hope that others might succeed in improving it. The successful completion of a plan or an investigation seemed to call for far more praise, in his mind, than originality in conception or ability in treatment.

Newcomb's last year was spent in a courageous struggle to work in spite of much physical suffering caused by an incurable disease. As soon as he knew that time was limited for him, almost all his remaining energy was devoted to the completion of an investigation which had been in his mind for many years. It was sent to the printer towards the end of June, and he died three weeks later. Thus passed away one of the great pioneers of American science, and one who also attained a high place in the ranks of those whose merits are judged to be worthy of honor apart from time or place.

E. W. Brown. 